\title{
P060: Surveillance and control of community-associated methicillin-resistant Staphylococcus aureus in Geneva, Switzerland, $2002-2012$
}

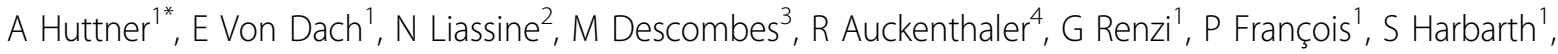 \\ P Sudre ${ }^{5}$, Cantonal Antibiotic Resistance Group of Geneva ${ }^{1}$
}

From 2nd International Conference on Prevention and Infection Control (ICPIC 2013)

Geneva, Switzerland. 25-28 June 2013

\section{Introduction}

Community-associated methicillin-resistant Staphylococcus aureus (CMRSA) was first reported in Geneva in 2002; a prospective surveillance system based on voluntary reporting was then established.

\section{Objectives}

We report trends in CMRSA infections in Geneva Canton from 2002 through 2012.

\section{Methods}

The Cantonal Antibiotic Resistance Group, representing Geneva's Department of Health, University Hospitals and public and private laboratories, defines a CMRSA case as (1) a clinical infection from which MRSA is isolated in any adult or child with (2) no hospitalizations in the previous 12 months (excluding hospital stays for infants at birth), and (3) residence in Geneva Canton. Four laboratories as well as physicians from public hospitals and private practice participate. For each laboratory-reported case, a questionnaire is sent to the clinician for demographic and clinical information. Contact tracing is performed to detect clustering. Descriptive analyses were performed using Stata 12.

\section{Results}

There were 245 CMRSA cases in the 11-year surveillance period; the mean attack rate was 4.9 cases/100K inhabitants. Median age at diagnosis was 31 years (interquartile range, $13-48) ; 20 \%$ were under ten. Skin infections

${ }^{1} \mathrm{HUG}$, Geneva, Switzerland

Full list of author information is available at the end of the article dominated (82\%). There were no cases of necrotizing pneumonia, fasciitis or infection-related death. Incident cases predominated (75\%); recurrences did not increase over time. Most infections (75\%) occurred in persons without comorbidity; "chronic dermatologic condition" was the most common comorbidity $(15 / 48,31 \%)$ followed by diabetes mellitus $(8 / 48,17 \%)$. Fifty clusters were identified, most being family-related. After peaking at 8.4 cases/ $100 \mathrm{~K}$ inhabitants in 2005, CMRSA incidence has since plateaued at a mean of 5.5 cases $/ 100 \mathrm{~K}$ inhabitants.

\section{Conclusion}

After peaking in 2005, CMRSA infections appear to have stabilized despite continuous introduction of new strains. The surveillance system and related measures appear to be successful in containing transmission in Geneva Canton.

\section{Disclosure of interest}

None declared.

\section{Author details}

${ }^{1}$ HUG, Geneva, Switzerland. ${ }^{2}$ Dianalabs, Geneva, Switzerland. ${ }^{3}$ Unilabs, Geneva, Switzerland. ${ }^{4}$ Synlab, Geneva, Switzerland. ${ }^{5}$ DGS, Geneva, Switzerland.

Published: 20 June 2013

doi:10.1186/2047-2994-2-S1-P60

Cite this article as: Huttner et al: P060: Surveillance and control of community-associated methicillin-resistant Staphylococcus aureus in Geneva, Switzerland, 2002 - 2012. Antimicrobial Resistance and Infection Control 2013 2(Suppl 1):P60

\section{()

C 2013 Huttner et al; licensee BioMed Central Ltd. This is an Open Access article distributed under the terms of the Creative Commons Attribution License (http://creativecommons.org/licenses/by/2.0), which permits unrestricted use, distribution, and reproduction in any medium, provided the original work is properly cited. 